ORIGINAL ARTICLE

\title{
Prevalence of depressive symptoms among the clients maintained in methadone maintenance treatment programme at Tribhuvan University Teaching Hospital.
}

\author{
Pathak N1, Ojha SP2 , Sharma VD
}

1. Consultant, Department of Psychiatry, Armed Police Force Hospital, Nepal 2. Professor and Head, Department of Psychiatry, IOM, Kathmandu, Nepal 3. Professor, Department of Psychiatry, IOM, Kathmandu, Nepal.

E-mail *Corresponding author: nishitapathak@hotmail.com

\begin{abstract}
Introduction: Depression is widely prevalent among the former opioid addicts in Methadone Maintenance Treatment (MMT). It is important to be aware of its severity as it plays a crucial role in methadone dosage, length of time in treatment and the relapse rate. The co-existence of depression is seen to worsen the prognosis in outcome of MMT.

Objective: This study aimed to study the prevalence of the symptoms of depression among MMT clients.

Method: This is a descriptive and Cross-Sectional study done in 60 MMT clients attending the out patients clinic in Tribhuwan University Teaching Hospital, Nepal. A structured proforma was constructed obtaining the data regarding age, sex, religion, occupation, marital status, literacy rate and socio-economical status. Depressive symptoms were evaluated using 21-item BDI scale.

Result: Depressive symptoms were found in $63.3 \%$ of the patients. $38.3 \%$ had mild to moderate depression, $15 \%$ had moderate to severe, and $11.7 \%$ had severe level of depressive symptoms. The depressive symptoms were most prevalent among females (90\%) and age group 40-50 years. The prevalence of depressive symptoms were more in unmarried (82\%), unemployed(65\%), lower socio-economic class $(71 \%)$ and completing only secondary level in education $(73 \%)$.

Conclusion: The major risk factors for depression among former opioid users were female gender, unmarried, low education level, unemployment and low socio-economic status.
\end{abstract}

Keywords: Methadone Maintenance treatment program, opioids, depressive symptoms.

\section{INTRODUCTION}

Substance users are the individuals who abuse opioids, alcohol, cocaine, benzodiazepines, caffeine, nicotine etc. Methadone is a long acting opioids which is used as the treatment for opioid users. Patients taking methadone remains physically dependent on methadone and withdrawal from methadone is much slower than opioids avoiding serious side effects. Methadone has cross tolerance with other opioids as well establishing itself as a well- tested safe treatment for all opioids withdrawals.

Substance users are seen to have various psychiatric and personality disorders. These disorders can be anxiety, depression, psychosis, neurosis, antisocial or personality disorders., 1,2,3 Substance users are also found to have higher criminal record and higher prevalence of HIV infection. Some psychiatric disorders preceded the onset of drug dependence while others are precipitated by the chronic drug use. ${ }^{4,5}$ Clinical 
studies have shown that half of the opioid dependent individuals report lifetime depression, whereas one-third have depressed mood during drug abuse to addiction therapy.3,4,5 The prevalence of psychiatric comorbidity among opioid users is relevant to treatment provider as client respond poorly to treatment. It has also been found that severity of psychiatric co-morbidity is inversely proportionate to the degree of treatment success. Till date no studies has been conducted in Nepal to see the prevalence of depression among Methadone Maintenance Treatment Program (MMTP) patients. Thus this study was carried out to see the prevalence of Depressive symptoms among MMTP clients in Methadone Clinic in Tribhuwan University Teaching Hospital, Nepal which is one of the only two Methadone Clinics in Nepal.

\section{MATERIAL AND METHOD}

This was a cross sectional and descriptive study conducted in Methadone clinic of Tribhuwan University Teaching Hospital which is operated by Psychiatric Department. 60 former opioid user Clients attending the Methadone clinic for a period of 4 months were taken into study. Every case was explained about the purpose of the study and the verbal consent was taken. Data were collected regarding the patient's age, gender, marital status, occupation, education and socio economic status. A semi- structured pro-forma was filled up containing questionnaire of Beck Depression Inventory (BDI). The collected data was profiled using Microsoft Excel worksheet and analyzed using SPSS software version 11.5. Inclusion criteria were clients on regular Methadone maintenance treatment program for at least four months and methadone Clients who gave written consents for participating in the study. Methadone clients using other psychoactive substances like alcohol, cannabis, brown sugar etc. besides methadone were excluded from the study. Methadone maintenance clients diagnosed with medical illness like HIV, chronic hepatitis with B or $\mathrm{C}$ virus, diabetes mellitus, Hypertension, stroke, cardiac disease etc. or surgical illness like cellulitis, abscess, deep vein thrombosis etc. were also excluded from the study.

\section{RESULT}

Majority of the clients in MMTP belonged to age group 30-39 (50\%) years.Most of the patients $96.7 \%$ of cases were male and only $3.3 \%$ were female. About $46.7 \%$ of the methadone maintenance clients were unmarried and 18\% were separated. In this study majority of cases were Newars (56\%) followed by Mongolians, Chhetris and Brahmins with 16.7\%, 16.7\% and $10 \%$ respectively. Around $75 \%$ of cases were Hindus, $6.7 \%$ were Buddhists and $18.3 \%$ were Muslims. $38.3 \%$ of cases had finished their secondary level education with 33.3\% completing higher level (graduates and post graduates). Majority of cases in our study attending MMTP were unemployed (65\%), 17\% were in business, $13 \%$ were clerks and $5 \%$ were students. $81 \%$ of patients belonged to middle class group and $11.7 \%$ belonged to lower class group. (Table 1)

In this study, $63.3 \%$ of the cases had symptoms of depression with varying severity. According to different level of weighted score of Beck Depression Inventory (BDI), 35\% had no depressive symptoms, $38.3 \%$ had mild symptoms of depression, $15 \%$ had moderate to severe depressive symptoms and $11.7 \%$ had severe depressive symptoms.

Depressive symptoms among methadone maintenance treatment program showed highest prevalence among age group 40-49 years (90\%), female gender $(100 \%)$, Mongolians $(80 \%)$, Buddhist religion (100\%) and unmarried (82\%). Similarly clients in lower socio-economical status $(71 \%)$ and completing only secondary level of education (73\%) also had depressive symptoms more often.

Distribution of the respondent according to presence and severity of depression after weighted scoring from beck depression inventory (BDI) is shown in figure 1 and figure 2 respectively. The presence of depressive symptoms means score more than 10 in 21 item in BDI. No depression means score of 0 to 9 in BDI. Mild to moderate depression means score of 10 to 19 in BDI, moderate to severe means score of 20 to 29 in BDI and severe means more than 30 in BDI. 
Table no. 1: Socio-demographic distribution

\begin{tabular}{|c|c|c|c|}
\hline \multicolumn{2}{|l|}{ Demographic profile } & \multicolumn{2}{|l|}{ DEPRESSION } \\
\hline & & FREQUENCY & PERCENTAGE \\
\hline \multirow{3}{*}{ AGE GROUP } & $20-29(n=18)$ & 9 & 50 \\
\hline & $30-39(n=30)$ & 18 & 60 \\
\hline & $>40(n=12)$ & 11 & 91 \\
\hline \multirow{3}{*}{ RELIGION } & Hindu $(n=45)$ & 27 & 60 \\
\hline & Buddhist( $n=11)$ & 7 & 63 \\
\hline & Christian $(n=4)$ & 4 & 100 \\
\hline \multirow{3}{*}{ MARITAL STATUS } & Single $(n=28)$ & 23 & 82 \\
\hline & Married $(n=14)$ & 3 & 21 \\
\hline & Separated $(n=18)$ & 12 & 66 \\
\hline \multirow{4}{*}{ CASTE } & $\operatorname{Brahimin}(\mathrm{n}=6)$ & 4 & 66 \\
\hline & Chettri(n=10) & 4 & 40 \\
\hline & Newar(n=34) & 22 & 64 \\
\hline & Mongolian $(n=10)$ & 8 & 80 \\
\hline \multirow{4}{*}{ EDUCATION } & Primary $(n=4)$ & 2 & 50 \\
\hline & Secondary $(n=23)$ & 17 & 73 \\
\hline & Intermediate $(\mathrm{n}=13)$ & 9 & 69 \\
\hline & Higher $(n=20)$ & 10 & 50 \\
\hline \multirow{4}{*}{ OCCUPATION } & Unemployed $(\mathrm{n}=39)$ & 32 & 82 \\
\hline & Student $(\mathrm{n}=5)$ & 2 & 67 \\
\hline & Bussiness $(n=10)$ & 0 & 0 \\
\hline & Service $(n=8)$ & 4 & 50 \\
\hline \multirow{3}{*}{$\begin{array}{l}\text { SOCIOECONOMIC } \\
\text { STATUS }\end{array}$} & Lower(n=7) & 5 & 71 \\
\hline & Middle $(n=49)$ & 31 & 63 \\
\hline & Upper $(\mathrm{n}=4)$ & 2 & 50 \\
\hline
\end{tabular}

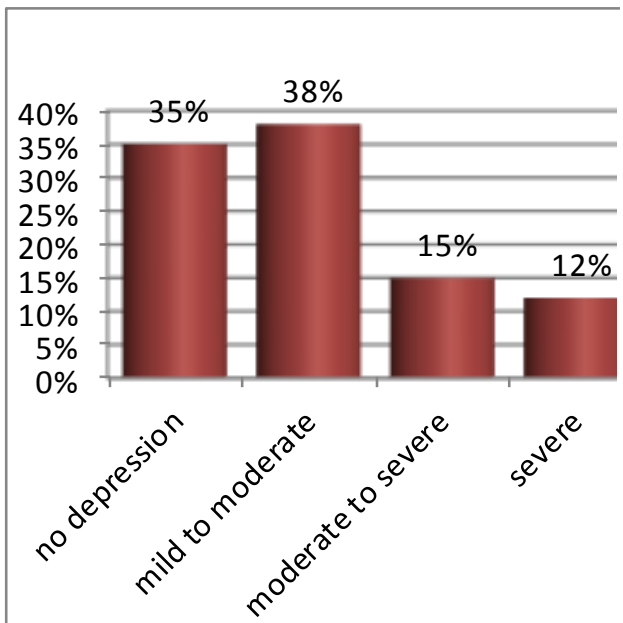

Figure 2: Distribution according to different levels of weighted score of Beck depression inventory (BDI).

\section{DISCUSSION:}

In our study there were very few females $(3.3 \%)$ in comparison to males. Weissman et al, in 1976 had $79 \%$ of Methadone Maintenance clients as males ${ }^{6}$. Karki et al in Nepal also found only 4 females using illicit drug in 1108 clients in Nepal in 1999.7 The majority of our clients in MMTP were of age group 30-39 years (50\%). These could be because most people start using opioids in early teens and adolescence period and are dependence by the time they are in thirties and forties. The dominance of Newars (56.7\%) in our study is because this study was conducted in Kathmandu valley where majority of people are Newars.

Our study showed strong association between depression and substance users attending MMTP clinic (63.3\%). T.C. Wild et al, a Canadian study showed $49.3 \%$ out of 679 opioid users had some forms of depression. ${ }^{8}$ Johnson M.E. et al in 2006 found $50 \%$ among 598 drugs users were depressed. ${ }^{9}$ Studies like Turrina C. et al and Lipsitz et al also had depressive symptoms among drugs users in frequency of $36.2 \%$ and $33 \%$ respectively. ${ }^{10,11}$ We also found depressive symptoms were common among unmarried 
clients $(82 \%)$. This finding was consistent with the studies of Sarkar et al and Icro et al where unmarried opioids users with depressive symptoms were $60 \%$ and $65.8 \%$ respectively. 12,13 This is also due to the fact that depressive illnesses are more common in both unmarried people and in opioids users. Similarly $65 \%$ of our clients who had depressive symptoms were unemployed. We know unemployment is one of the factors where young individuals get attracted to substance abuse most likely opioids. These groups of people also have tendency to get depressed very early and severely in comparison to the group who are employed and opioids user. $81.7 \%$ in MMPT clients with depressive symptoms belonged to middle class group where as only $11.7 \%$ belonged to lower class group. Economic status has been considered as one of the factors which determine drug using behaviors. This is in contrast to the study of Marmot MG et al., in 1984 where illicit drug users comorbidity were more common in among lower socio economical groups. ${ }^{14}$

In our study we used Beck Depression Inventory (BDI) scoring system. This system is simple and widely accepted. According to Beck Depression Inventory (BDI) score mild to moderate depression was more prevalent than moderate to severe and severe depression. Most of the depression in study belongs to age group 30-39 years which is the most productive age in an individual's life.

\section{CONCLUSION:}

Depressive illness is strongly associated among previous opioids users in MMTP clinics. Depressive illness was more common among age groups 40 to 49 years, female sex, unmarried and middle socio economical status. Mild to moderate depression was more frequent than moderate to severe or severe forms of depression in BDI score. More studies of these types are required to find other types of co morbidity in opioid users as they directly reflect the outcome to MMTP.

\section{REFERENCES:}

1. Drake, Swift, W.EHall, W. Prevalence, Severity and Correaltes of psychological Comorbidity among Methadone Maintenance Clients. Addiction. 1994;89:211-217.
2. Farrell, M., Howes, S., Taylor, C., et al. Substance misuse and psychiatric comorbidity: an overview of the OPCS national Psychiatric morbidity survey. Addictive Behaviours. 1998;23: 909-918.

3. Kessler, R.C., McGonagle, K. A., Zhao, S., et al. Lifetime and 12 months prevalence of DSM-III-R psychiatric disorders in the United States: results from the National comorbidity Survey. Archieves Of General Psychaitry. 1994; 171: 205-208.

4. Rounsaville B, Weissman J, Kleber M.K et al. Heterogenicity of psychiatric diagnosis in treated Opiate addicts. Archieves of General Psychiatry. 1982; 39: 161-166.

5. Obrien C, Lewise C, Cornish J.W, et al. Priority action to comprove the care of person with cooccuring substance abuse and other mental disorder: A call to Action. Mental Health. 2004; 56:703-713.

6. Weissman, M.M., Slobetz, F., Prusoff, B., Mezritz, M., and Howard, P. Clinical Depression Among Narcotic Addicts Maintained on Methadone in the Community. American Journal of Psychiatry, 1976; 133: 1434-1438.

7. Karki BB. RAP survey among drug users in Nepal. Harm Reduction Planning Workshop. 1999; June 7.

8. Tom Callay, Tom Traurer, Leigh Munro, Greg Whelan. Prevalence of Psychiatric Disorder In a Methadone Maintenance Population.; Autralian and New Zealand Journal of Pyschiaty: 2001; 35(5):601-605.

9. Johnson $M E$, Neal DB, Brems C, Fisher DG. Depression as measured by the Beck Depression Inventory-II among injecting drug users. Assessment. 2006; 13(2):168-77.

10. Turrina $C$, Fiorazzo a, Turano A, Cacciani $P$, Regini C, Castelli F, Sacchetti E. Depressive disorders and personality variables in HIV positive and negative drug users. J Affect Disord. 2001; 65(1): 45-53.

11. Lipsitz JD, Williams JB, Bradbury M, Sorrell S. Psychopathology In Male And Female Intravenous Drug Users With And Without HIV Infection. Am J Psychiatry: 1994; 151(11): 1662-1668.

12. Sarkar, K., Panda, S., Das, N., E Sarkar, S. Relationship of national highway with injecting drug abuse and HIV in rural Manipur, India. Indian Journal of Public Health. 1997;4:49-51.

13. Icro Maremmani, Stefania Canoniero, Alessandro Tagliamonte. Methadone maintenance: stabilization dosages in patients with psychiatric co-morbidity; Journal For Addiction and Alcoholism: 1999; 2: 107-113.

14. Marmot, M.G., Shipley, M.J. and Rose, G. Inequalities in death-specific explanations of a general pattern? Lancet. 1984; i: 1003-1006. 